of the operating pressure, monsurement of the variable prossure and the design of the measuring head are then considered, followed by brief descriptions of the pneumatic measuring instruments and machines developed at the Laboratory. These include a pneumatic calliper and machines for the measurement of roforoneo ring gauges, reference plug gauges, and of thin-sheet material during production. Automatic equipment for the calibration of slip gauges is being developed. Pneumatic gauges with magnifications ranging from 1,000 to 20,000 can easily be attained, and with spocial equipment it is not difficult to reach a magnification of 100,000 . The study of the pnoumatic method was begun at the Laboratory during the Second World War, but it is only in the years since the War that the manufacture of pneumatic measuring instruments has been taken up by industry in the United Kingdom and overseas. The simplicity and precision of the method, together with its flexibility, are now well known to engineers, but the technique needs to be more generally known and utilized.

The nocessity for a third edition of No. 12 in the series ${ }^{1}$ indicates the popularity and value of this booklet, and also reflects the continuing attention paid to the extension of the temperature scale and to improvements in the testing of mercury thermometers. A brief reference is made to attempts to extend the International Practical Scale of Temperature below $-182.97^{\circ} \mathrm{C}$, the boiling-point of oxygen, but it was too early to refer to the other revisions which have been proposed for consideration at the thirteenth General Conference of Weights and Measures to bo held, probably, during 1968. The amended edition (1960) of the International Practical Temperature Scale of 1948 is printed in the appendix to the booklet.

The first edition of the parnphlet dealing with oquivalent metric values for use in scientific papers ${ }^{2}$ was drawn up by
F. A. Gould in 1948 under the guidance of Sir Charles Darwin, and was intended to assist authors and oditors to render numerical data expressed in British units easily intelligible to readers using the metric system. The revised edition is by $\mathrm{P}$. $\mathrm{H}$. Bigg and incorporatos modifications such as $\operatorname{deg} \mathrm{C}$ in place of ${ }^{\circ} \mathrm{C}$ for temperature difference. An addendum leaflet (dated December 1963) mentions the resolutions of the General Conference of Weights and Measures with respect to the ST system and the replacement of the litre by the cubic metre. Additional conversion factors are also given. In the new edition of the pamphlet on units of photometry, colorimetry and radiometry ${ }^{3}$, the sections on equivalent luminance and the scotopic system of photometry have been brought up to date, but the two questions on the definition of the properties under conditions of partial light-adaptation, and of the adoption of standard colour-matching functions appropriate to a 10-degree field of view, are left unresolved. Reference is, however, made to the C.I.E. (International Commission on Illumination) publications which deal with recent discussions of these questions.

\section{S. WEINTROUB}

${ }^{1}$ Hall, J. A., and Bauber, C. IR., Calibration of Temperature Measuring Instruments, third ed. (Dept. Scientific and Industrial Research National Physical Laboratory. Notes on
Pp. iv +55 . London: H.M.S. O., 1964.)

' Bigg, P. H. (revised by), The Inclusiom of Equivalent Metric Values in

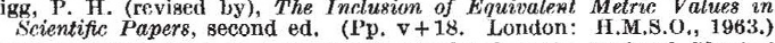
${ }^{3}$ Units and Standards of Measurement Employed at the National Physical Laboratory. II, Light : Photometry, Colorimetry and Radiometry, sccond cd. (Pp. iii + 10. London: H.M.S.O., 1964.)

"Table of Correction Functiom for Velocity of Lonyitudinal Waves in Cylindrical (1964.)

- Holder, D. W., and North, R, J., Schlieren Methods. (Dept. Scientifle and Industrial Research, National Physical Laboratory. Notes on Applied Science, No. 31. Pp. $\mathrm{x}+108$ with 29 plates. London:
H.M.S.0., 1983.)

'Evans, J. C., and Morgan, I. G., Principles of Pneumatic Gauging. (Dept. Scientific and Industrial Research, Notes on Applied Science, No. 34.
Pp. iii +48 with 8 plates. London: H.M.S.O., 1964.)

\title{
BUILDING RESEARCH IN AUSTRALIA
}

$\mathrm{A}^{\mathrm{T}}$ TTENTION was recently directed to the work of the Building Research Station, Garston, Watford, Herts (Nature, 205, 30;1965), and it is therefore of eonsiderablo interest to read of the activities in the same field of the othor countries, in particular in the Commonwealth; in this context the annual report, 1963-1964, of the Division of Building Research of the Commonwealth Scientific and Industrial Research Organization of Australia is welcome (C.S.I.R.O., Molbourne; 1965; pp. vi+64). As with our own building research organization, the work of this Division covers a wide and ever-increasing range of research projoets in building tochnology to meet modern demands for higher standards of buildings large and small and in solving fresh problems of raw matorials and application which aro constantly arising both in the trade and in the more theoretical aspects of building science. In this report the subjects are treatod alphabotically following an introduction which roviews the work of the Division for the year.

In the section on architectural acousties, activitios were mainly concerned with noise in the community; reverberation and transmission chambers; absorption studies, and noise of rain on metal roofs. Work on bituminous materials included studies of durability of roofing bitumens and rupture of bituminous roofing fabrics. In the clay and clay products section, regional studies of Australian clays continued and other work embraced ceramic materials and processes, lightweight ceramic products, long-torm expansion of clay products and clay technology in general. Under concrete the subjects reportod on are lightweight concrete; efflorescence on concrete products; concrete roofing tiles; croep and shrinkage of concreto in structures, and concrete floors. Gypsum plaster is discussed under titles: physical chemis- try of calcium sulphate, special gypsum products and fibrous plaster. The subject of joints is mainly devoted to materials and methods available for scaling them in exterior walls of buildings to prevent rain penetration to the interior, and glazing sealants are also considered. As regards mortar, investigations are still proceeding into the effect of composition and age on the strength, modulus of elasticity, shrinkage and creep properties, a subject apparently somewhat neglected elsewhere.

The paint section has been concerned with mould growth on painted surfaces, sufficiontly prevalent in Australia to have a decided nuisance value and consequent maintenance expenditure; various fungicides mixed with paints have been experimented with, but it was found that these do not invariably prevent mould growth; so far paints containing zinc oxide appear to give the best performance in this respect.

Structural testing and design are discussed in terms of flat plates, loads during construction and direct design. Thermal investigations includo measuremonts of temperntures inside buildings and studies of solar radiation as regards intensity and direction effects on buildings. Tropical building investigations in this section have been in connexion with a survey of limestone resources and laboratory work on samples from Papua and New Guinea, and with other indigenous materials for masonry construction; in this subject a new series of publications entitled T'ropical Building Research Notes has been initiated by the Division and will be issuod about six timos a year. The report concludes with an account of miscellanoous investigations, including the determination of crystal structures of interest to building materials, plastics for building repairs, and studies of foundation-structure interaction. 